\title{
Cost-effectiveness of anterior surgical decompression surgery for cervical degenerative disk disease: a systematic review of economic evaluations
}

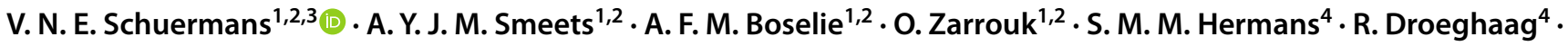 \\ I. Curfs ${ }^{4}$ S. M. A. A. Evers ${ }^{3,5,6} \cdot$ H. van Santbrink ${ }^{1,2,3}$
}

Received: 6 July 2021 / Revised: 6 July 2021 / Accepted: 26 January 2022 / Published online: 28 February 2022

(c) The Author(s) 2022

\begin{abstract}
Purpose No clear consensus exists on which anterior surgical technique is most cost-effective for treating cervical degenerative disk disease (CDDD). One of the most common treatment options is anterior cervical discectomy with fusion (ACDF). Anterior cervical discectomy with arthroplasty (ACDA) was developed in an effort to reduce the incidence of clinical adjacent segment pathology and associated additional surgeries by preserving motion. This systematic review aims to evaluate the evidence regarding the cost-effectiveness of anterior surgical decompression techniques used to treat radiculopathy and/or myelopathy caused by CDDD.

Methods The search was conducted in PubMed, EMBASE, Web of Science, CINAHL, EconLit, NHS-EED and the Cochrane Library. Studies were included if healthcare costs and utility or effectivity measurements were mentioned.

Results A total of 23 studies were included out of the 1327 identified studies. In 9 of the 13 studies directly comparing ACDA and ACDF, ACDA was the most cost-effective technique, with an incremental cost effectiveness ratio ranging from $\$ 2.900 /$ QALY to \$98.475/QALY. There was great heterogeneity between the costs of due to different in- and exclusion criteria of costs and charges, cost perspective, baseline characteristics, and calculation methods. The methodological quality of the included studies was moderate.

Conclusion The majority of studies report ACDA to be a more cost-effective technique in comparison with ACDF. The lack of uniform literature impedes any solid conclusions to be drawn. There is a need for high-quality cost-effectiveness research and uniformity in the conduct, design and reporting of economic evaluations concerning the treatment of CDDD.
\end{abstract}

Trial registration PROSPERO Registration: CRD42020207553 (04.10.2020).

Keyword Cervical degenerative disk disease $\cdot$ Anterior decompressive surgery $\cdot$ Cost-effectiveness $\cdot$ Cost-utility . Economic evaluations

Abbreviations

ACD Anterior cervical discectomy

ACDA Anterior cervical discectomy with arthroplasty

Communicated by NETHERLANDS.

V. N. E. Schuermans

Valerie.schuermans@mumc.nl

1 Department of Neurosurgery, Maastricht University Medical Center, Maastricht, The Netherlands

2 Department of Neurosurgery, Zuyderland Medical Center, Henri Dunantstraat 5, 6419 PC Heerlen, The Netherlands

3 CAPHRI School for Public Health and Primary Care, Maastricht University, Maastricht, The Netherlands
ACDF Anterior cervical discectomy and fusion

CASP Clinical adjacent segment pathology

CCEMG Campbell and Cochrane Economics Methods Group

CDDD Cervical degenerative disc disease

4 Department of Orthopedic Surgery and Traumatology, Zuyderland Medical Center, Heerlen, The Netherlands

5 Department of Health Services Research, Focusing on Value-Based Care and Ageing and Department of Family Medicine, Maastricht University, Maastricht, The Netherlands

6 Center of Economic Evaluation and Machine Learning, Trimbos Institute, Netherlands Institute of Mental Health and Addiction, Utrecht, The Netherlands 


$\begin{array}{ll}\text { CEA } & \text { Cost-effectivity analysis } \\ \text { CHEC } & \text { Consensus health economic criteria } \\ \text { CPT } & \text { Current procedural terminology codes } \\ \text { CUA } & \text { Cost-utility analysis } \\ \text { DRG } & \begin{array}{l}\text { Diagnosis related group codes } \\ \text { Evidence for Policy and Practice Informa- } \\ \text { EPPI-Centre } \\ \text { tion and Coordinating Centre }\end{array} \\ \text { EQ-5D-5L } & \text { EuroQol-five dimensions } \\ \text { ICER } & \text { Incremental cost effectiveness ratio } \\ \text { QALYs } & \text { Quality-adjusted life years } \\ \text { MNPa } & \text { Medicare national payment amounts } \\ \text { PROMs } & \text { Patient reported outcome measures } \\ \text { RCTs } & \text { Randomized controlled trials } \\ \text { SF-36/12/6 } & \text { Short Form Health Survey } \\ \text { USD } & \text { United States Dollars } \\ \text { WTP } & \text { Willingness to pay }\end{array}$

\section{Introduction}

No consensus exists on which anterior surgical technique is more cost-effective to treat cervical degenerative disk disease (CDDD) resulting in cervical degenerative radiculopathy and/or myelopathy.

The incidence of degenerative pathologies is significantly increasing as the population ages $[1,2]$. Generalized spinal disk degeneration occurs in more than $90 \%$ of adults past the 5 th decade of life [3]. This age group now represents $32.8 \%$ of the population in Europe and is projected to reach $40.6 \%$ by 2050 [2]. Complaints of radiculopathy and/or myelopathy differ in severity, but are often disabling. This leads to restrictions in daily life and loss of professional capability with absenteeism as a result, leading to an increase in societal costs. Healthcare costs are driven up further when patients require surgical treatment, in combination with associated hospitalization and rehabilitation.

One of the most common procedures for treating patients with radiculopathy and/or myelopathy as a consequence of single- or multilevel CDDD is anterior cervical discectomy with fusion (ACDF) or without (ACD) [4]. A recent study by Neifert et al. predicts a significant increase in ACDFprocedures in those aged 45-54 in the next 20 years which involves the working population [5-7]. Both techniques show good short-term clinical results [8]. However, patientreported satisfaction gradually drops to $68-96 \%$ after $7-20$ years $[9,10]$. This is thought to be the consequence of the development of new complaints of radiculopathy and/or myelopathy at a segment adjacent to the site of previous surgery, also known as clinical adjacent segment pathology (CASP) [11]. The underlying mechanism is thought to be compensation for the loss of motion in the fused segment, resulting in overstraining of the adjacent segments in addition to progression of natural degeneration [12-14]. This occurs at an estimated cumulative rate of 1.6 to $4.2 \%$ per year after fusion surgery. Patients with CASP often require additional surgery, which drives up health-care costs even further $[11,15,16]$.

Anterior cervical discectomy with arthroplasty (ACDA) was developed in an effort to reduce the incidence of CASP by preserving motion in the operated segment(s). Previously conducted research has shown that no significant differences in clinical or radiological outcomes among these different techniques $[12,17,18]$. Multiple trials with long-term follow-up report significantly lower additional surgery rates for ACDA in comparison with ACDF, both for single- and multilevel surgeries [19-23]. Proper interpretation remains difficult however, as reported additional surgery rates vary strongly, from 0 to $11.6 \%$ for ACDA, and 0 to $18.2 \%$ for ACDF in 2-7 years follow-up [24-26].

Presently, ACDA is often discouraged as the implant costs are higher than those for ACDF while the clinical outcomes are similar. However, preventing additional surgeries due to CASP and new complaints might be a reason for ACDA to be a more cost-effective technique in the long run.

There are high quality systematic reviews available concerning the clinical effectiveness of these different anterior decompression surgeries for CDDD [27, 28]. To date, only one systematic review, dating from 2014 , and one narrative review have been conducted concerning the cost-effectiveness of these techniques. Conclusive evidence is therefore still lacking $[29,30]$. This systematic review aims to evaluate the current evidence on cost-effectiveness of anterior cervical decompressive surgeries in patients with CDDD resulting in radiculopathy and/or myelopathy. The methodological quality of the included studies will be determined to be able to draw conclusions concerning the level of evidence.

\section{Materials and methods}

\section{Review protocol}

This systematic review was executed in accordance with the PRISMA statement [31, 32] and the five-step approach on preparing a systematic review of economic evaluations by Van Mastrigt et al. [33-35]. The study protocol has been published in the PROSPERO-database before commencing the study (registration number CRD42020207553).

\section{Search strategy and eligibility criteria}

Searches for clinical and economic studies were systematically carried out in PubMed, EMBASE (OVID), Web of Science (Clarivate Analytics), CINAHL (EBSCO), Econlit (EBSCO), NHS EED (CRD) and the Cochrane Library (CENTRAL) and Cochrane database of Systematic 
Reviews. The search was conducted without using filters. The final search was conducted on September 16th, 2020 (Appendix File 1).

Studies were included if they met all of the following eligibility criteria: (1) CDDD resulting in radiculopathy and/or myelopathy, (2) anterior decompressive surgery (3) cost sources, health care and societal perspective costs, total costs (health care perspective costs plus societal perspective costs), costs per quality-adjusted life years (QALY) (4) utility measurement tool, gained qualityadjusted life years.

\section{Study selection and data collection}

Duplicates were removed, potential studies were screened on title and abstract, and full texts were assessed by two independent researchers (VS, XOZ) using all eligibility criteria. This assessment was done in "Rayyan" [36]. If necessary, consensus was reached between both authors through discussion.

Randomized controlled trials (RCTs), prospective comparative studies concerning cost-effectiveness and both full and partial economic evaluations were included. Cost-utility analyses (CUA) and cost-effectiveness analyses (CEA) were also included if they had a retrospective study design.

The following data were extracted from the included articles; study design, year of publication, country, baseline characteristics of patients, diagnosis, type of interventions, primary and secondary outcome measures as described above. The complete data collection sheet can be found in Appendix File 2. Cost-effectiveness of two interventions can be compared using the incremental cost-effectiveness ratio (ICER), where the difference in costs between two interventions will be divided by the difference in their effect [37].

\section{Quality assessment}

The methodological quality of the economic evaluations was assessed by two independent reviewers (VS, OZ) with the checklist of Consensus on Health Economic Criteria (CHEC) by Evers et al. [38]. The CHEC-list consists of 19 categories, including performed discounting and sensitivity analysis, where a single point can be assigned to each category with a maximum score of 19 points. A CHEC-list score between 15 and 17 points is rated as average methodological quality [38]. Risk of bias was assessed by two independent reviewers (VS, $S M$ ). RCTs were assessed with the Cochrane Risk of Bias tool in Review Manager 5.3 [39]. Non-randomized controlled trials were be assessed with the Risk of Bias in Non-Randomized Studies of Interventions
(ROBINS-I) tool [40]. Full risk of bias assessment sheets and CHEC list scores are outlined in Appendix File 3 and Appendix File 4.

\section{Analysis}

All costs were converted to American Dollars to the reference year 2020 with the use of a web-based tool, developed by the Campbell and Cochrane Economics Methods Group (CCEMG) and the Evidence for Policy and Practice Information and Coordinating Centre (EPPI-Centre) (v.1.6) [41]. If the index year was not mentioned in the study, subsequently the last year of patient inclusion or the year of publication was used as index year. Heterogeneity was assessed with the Chi-squared test in Review Manager 5.3 [42]. Descriptive statistics were used and reported in a narrative summary according to the Cochrane handbook [39]. Sensitivity analyses of the different study designs were checked for consistency of results.

\section{Results}

\section{Study selection}

The systematic search in the databases yielded 1948 articles, 1327 of which remained after removal of duplicates. Of the 28 studies eligible for inclusion, 6 studies were based on data of overlapping patient cohorts. Of these, the most recent studies with the largest patient cohort and the longest follow-up time were included. One study was included through cross-referencing [43], resulting in a total of 23 studies [44-65]. A flowchart of the selection process is presented in Fig. 1.

\section{Study characteristics}

Characteristics and results of the included studies are displayed in Table 1. Chi-squared was larger than 99\%, indicating a very high heterogeneity between studies, and a metaanalysis was therefore not performed. Publication years ranged from 2005 [52] to 2019 [45]. Follow-up time ranged from $1[48,49,58]$ to 10 years post-operative [55]. Probabilistic models simulated 5 years $[45,56]$ to life-long follow-up [51]. Twenty studies were performed in the United States of America, one in Canada [50], one in Korea [45] and one in Spain [53]. Three prospective economic evaluations [48, $58,66]$ were included; all others were retrospective CEAs or CUAs. In a total of 5 studies, a Markov Analysis was performed [44, 45, 47, 51, 56].

Thirteen studies compared ACDA and ACDF directly $[43-47,56,60-65,67,68]$ and four studies compared 


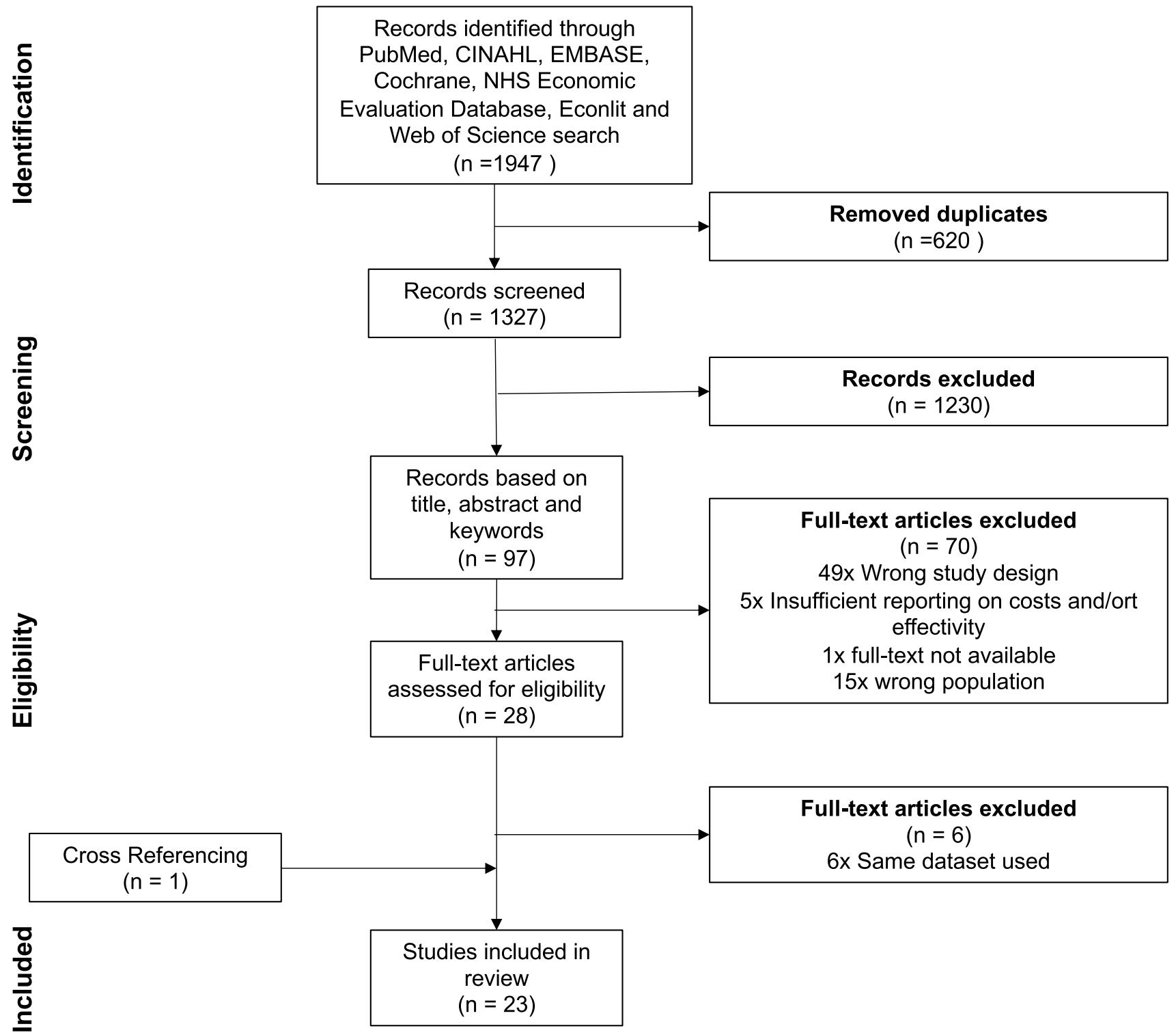

Fig. 1 The PRISMA flowchart of the inclusion process

ACDF with posterior decompressive techniques [48, 49, $58,66]$. The six remaining studies described costs without (surgical) cohort $[51,54,57]$ or compared auto- and allograft techniques for ACDF, but costs are represented separately [Table 1] [52, 53, 55]. There was a large variety in the evaluated study populations, as some studies only included patients with radiculopathy $[46,47,49,51,53]$ or myelopathy $[48,66]$, and other studies specifically evaluated singlelevel surgeries $[46,49,54,55,59,63,69,70]$ in contrast to those that only assessed multi-level surgeries $[43,48,56$, $61,64]$.

Cost-effectiveness was expressed in ICER in 14 of the included studies [44, 45, 51-53, 56, 59-65]. Fifteen studies determined QALYs based on derivatives of the
Short-Form (SF) questionnaires, of which 8 studies used the SF-6D [66], or converted the SF-12 [44, 46, 64] or SF-36 [52-54, 56, 59-61, 69, 70] to the SF-6D to determine a cumulative or yearly QALY gain. Three studies used EuroQol-five Dimensions (EQ-5D-5L) to determined QALYs $[49,57]$. One study expressed clinical effectivity in value of work productivity and net economic benefit [43]. All studies reported healthcare costs, seven of which also reported costs from a societal perspective $[47,49,54$, 57, 64, 71]. Costs were calculated based on costs, charges or a combination of both. Charges were based on Medicare National Payment amounts (MNPa) by Current Procedural Terminology codes (CPT) and Diagnosis Related Group codes (DRG) in eighteen studies [44, 47-49, 51, 


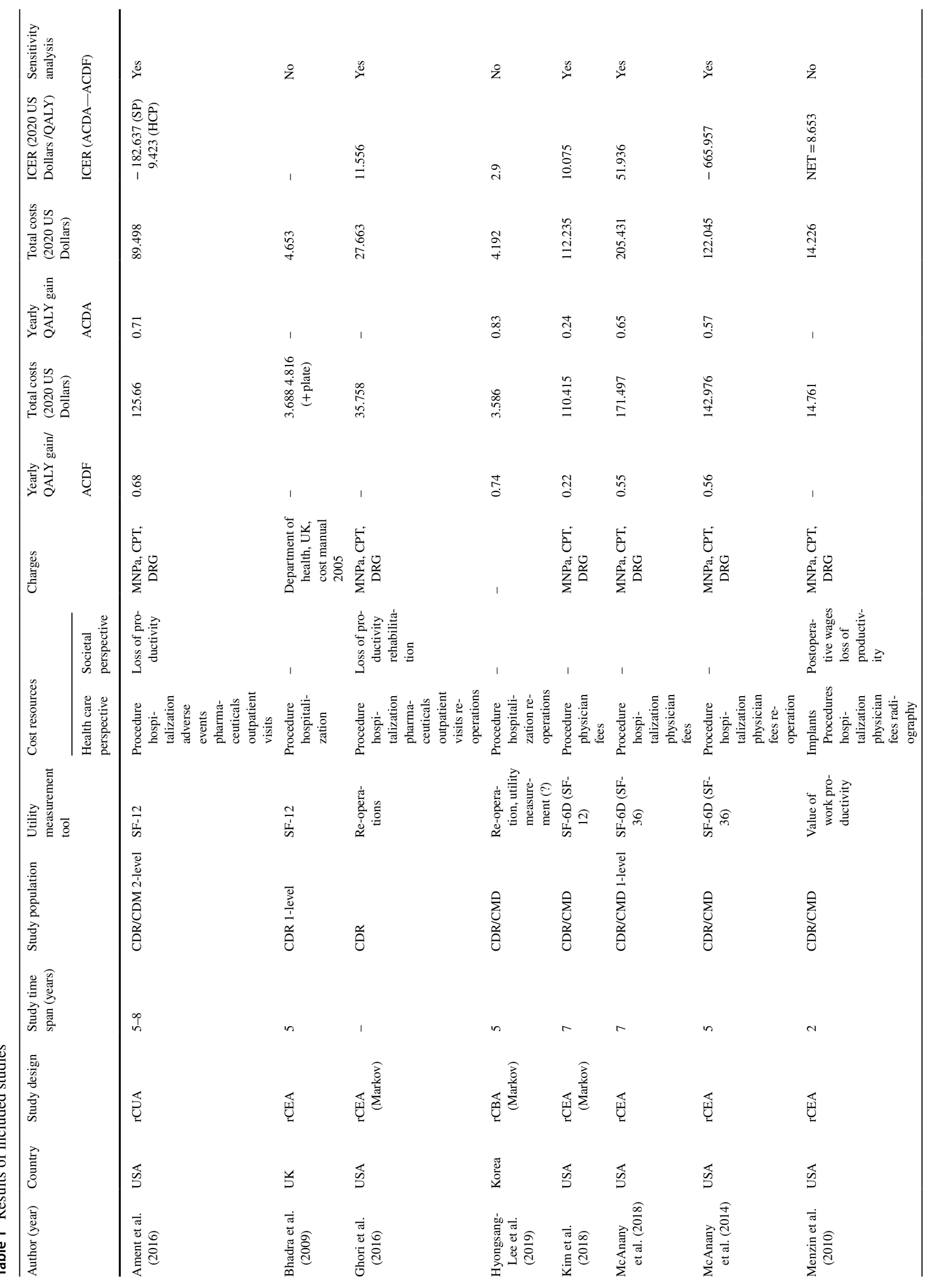




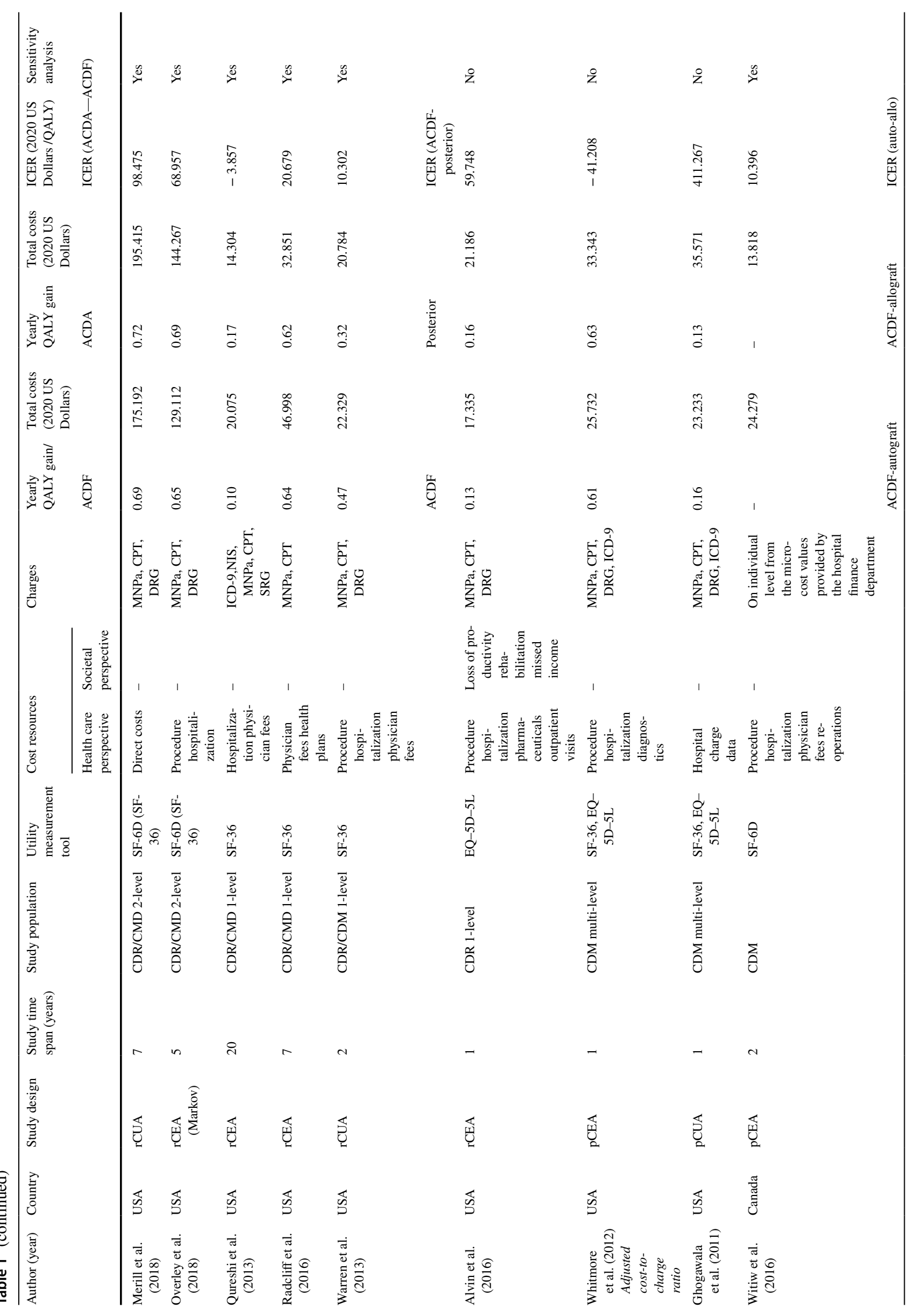




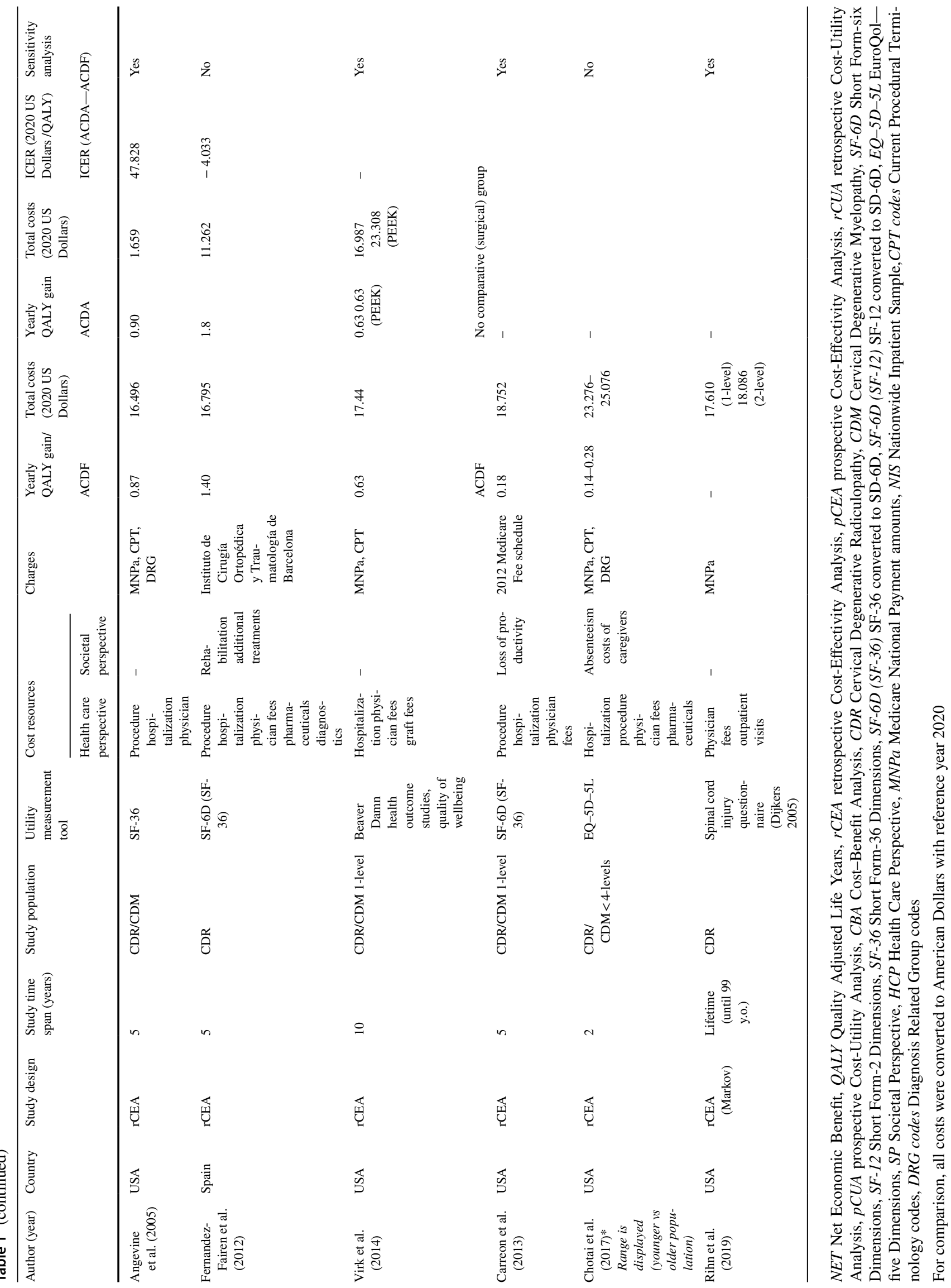


52, 54-65] for hospitalization, procedure and physicians. Reported costs varied from physician and procedural costs only, to all resource costs associated with an intervention, including costs for caregiver time or absenteeism.

\section{Study results}

In 9 of the 13 studies directly comparing ACDA and ACDF, ACDA was the most cost-effective technique [43-45, 47, 56, $59,61,65,69]$. The ICER of ACDA over ACDF ranged from \$2.900/QALY [45] to \$98.475/QALY [61], three of which passed $\$ 50.000 / \mathrm{QALY}$, which is commonly regarded as the willingness to pay threshold (WTP). All studies showed comparable QALY-gain with minimal differences. Figure 2 displays the total costs and total QALY gain for ACDA and ACDF. Figure 3 illustrates an ICER plane of 10 of the 13 studies comparing ACDF directly to ACDA, the other three are not depicted as there was no QALY-gain reported [46, 47].

The QALY-gain or cumulative QALYs were mentioned in seventeen studies [44, 45, 48, 49, 52, 54-65]. The yearly QALY-gain ranged from 0.10 [63] to 0.87 [52] for ACDF and from 0.17 [63] to 0.83 [45] for ACDA. Costs for subgroups such as radiculopathy and myelopathy or single- and multilevel surgery could not be compared due to the heterogeneity in reporting costs. Cost ranges are mentioned instead of means due to the large heterogeneity in calculation and reporting of costs between studies. Healthcare costs from the healthcare perspective ranged from $\$ 3.586$ [45] to $\$ 175.192$ [61] for ACDF and from $\$ 4.192$ [45] to $\$ 205.431$ [59] for ACDA. When including societal costs, costs ranged from $\$ 35.758$ [47] to $\$ 125.660$ [64] for ACDF and from $\$ 14.226$ [43] to $\$ 89.498$ [64] for ACDA.

\section{Quality of identified studies}

The methodological quality of each economic evaluation was critically assessed according to the CHEC-criteria, which can be found in Appendix File 3. CHEC scores ranged from 8 to 18 , with a mean score of 14.2. This indicates an overall moderate methodological quality.

The risk of bias assessment can be found in Appendix File 4. Based on the criteria for randomized studies overall risk of bias was high. According to the ROBINS-I tool, the overall quality of non-randomized studies was moderate.

\section{Discussion}

The objective of this systematic review was to evaluate the current evidence on cost-effectiveness of anterior cervical decompressive surgeries in patients with CDDD resulting in radiculopathy and/or myelopathy. The most important conclusion to be drawn from this review is the lack of literature on the subject and, more importantly, the large heterogeneity between studies in determining both costs and effectiveness. Solid conclusions can thus not be drawn regarding the most cost-effective technique to treat CDDD. Figure 2 reflects the large variety in results of the included study. These methodological challenges draw attention to the need for high quality cost-effectiveness research, and uniformity in methodology and reporting.

Radcliff et al. described similar heterogeneity in a recent publication about economics of cervical disk replacement [72]. There was large heterogeneity in health care and societal perspective costs due to differences in calculation methods of costs and/or charges, included costs, different in- and exclusion criteria and baseline characteristics. It is noteworthy to mention that the lowest costs are reported in studies conducted outside of the United States of America (United Kingdom, Spain and Korea). This is not surprising considering the prominent difference in healthcare systems.

The Panel on Cost-Effectiveness in Health and Medicine in the United States recommends performing cost-effectiveness studies from the societal perspective [73]. Nevertheless, only 6 out of 23 studies included in this review have reported on societal perspective costs. The variety in the calculation of costs and charges was reliant on the inclusion of costs such as hospitalization, physician fees, procedural costs, pharmaceuticals, rehabilitation, caregivers and work absenteeism. Furthermore, it should be noted that some studies evaluated patients with radiculopathy or myelopathy alone, and other studies included all CDDD patients. There was also an important difference in the inclusion of singlelevel or multi-level surgeries. Another important factor is the large variation in study follow-up time. This may have a significant impact on cost-effectiveness as both the costs and clinical effectivity might be influenced by the occurrence of CASP and possible additional surgery rates $[11,16]$.

The clinical effectivity of the surgical interventions was determined based on different utility measurement tools. Most studies used derivatives of the SF-questionnaires and converted these to SF-6D, however these converted questionnaires cannot equally be compared to their originals [74]. The reported effectiveness of the evaluated interventions was comparable in all studies and the difference in QALY-gain can be interpreted as not clinically significant. This is in line with previous literature that shows no clinical difference between ACDA and ACDF [17, 18].

The theory that ACDA may be the superior surgical intervention for symptomatic CDDD has been the topic of discussion for multiple years. ACDA was developed in an effort to maintain motion and thereby prevent overstraining of the adjacent segments and consequent CASP. In spite of higher implant costs, ACDA might be a more cost-effective technique on the long term as CASP 
and additional surgeries with associated costs could be avoided. Due to the variances in reported data on costs and clinical effectivity, stated cost-effectiveness cannot equally be compared. However, there seems to be a trend of higher cost-effectiveness in ACDA in comparison with ACDF. The WTP is dependent on the burden of disease and varies strongly per country. In this study, WTP was only mentioned in US-orientated studies, of which 12 upheld a WTP of \$50.000/QALY and 2 upheld a WTP $\$ 100.000 / \mathrm{Q} A L Y$. Three out of the 9 studies in favor of ACDA reported an ICER that passed the threshold of a WTP of $\$ 50.000 / \mathrm{QALY}, 2$ out of the 3 studies in favor of ACDF passed this threshold. It can be stated that both techniques are expensive, which gives rise to the question of which technique is most cost-effective.

Besides determining the most cost-effective technique, it is important to improve cost-effectiveness, either by reducing costs or by improving clinical effectivity. Patient profiling may play a significant role. More research is needed to investigate which baseline characteristics predict better patient-reported outcome measures (PROMs) post-operatively, which could influence surgical decision-making. Moreover, it is strongly recommended that future cost-effectiveness analyses should be prospective and conducted uniformly. It would be profitable to have guidelines for the conduct of economic evaluations in spine surgery to create uniformity in methodology and reporting, as has recently been published for osteoporosis research [75].

In contrast to the limited number of narrative reviews concerning economics of cervical spine surgery, we provide a detailed and systematic overview of relevant literature. The strength of this systematic review is its methodological quality, as it was executed in accordance with the proposed PRISMA statement [31, 32] and the five-step approach on preparing a systematic review of economic evaluations by Van Mastrigt et al. [33-35]. The main limitation that may have biased the result of this study was the inclusion of only full text and published studies but not conference proceedings, $\mathrm{PhD}$ dissertations or gray literature. Three studies were manufacturer-sponsored or had a possible financial benefit [53, 64, 69] and two studies did not provide information on funding $[46,55]$. Another limitation is that we did not differentiate between the costs of different manufacturers for disk protheses. We expect limited influence on our results, in contrast to an increase in heterogeneity of our data.

Results from this systematic review were mostly extracted from data from North-America and thus may not be relevant for other continents. Data from other continents, or even countries, is essential as costs between countries vary.

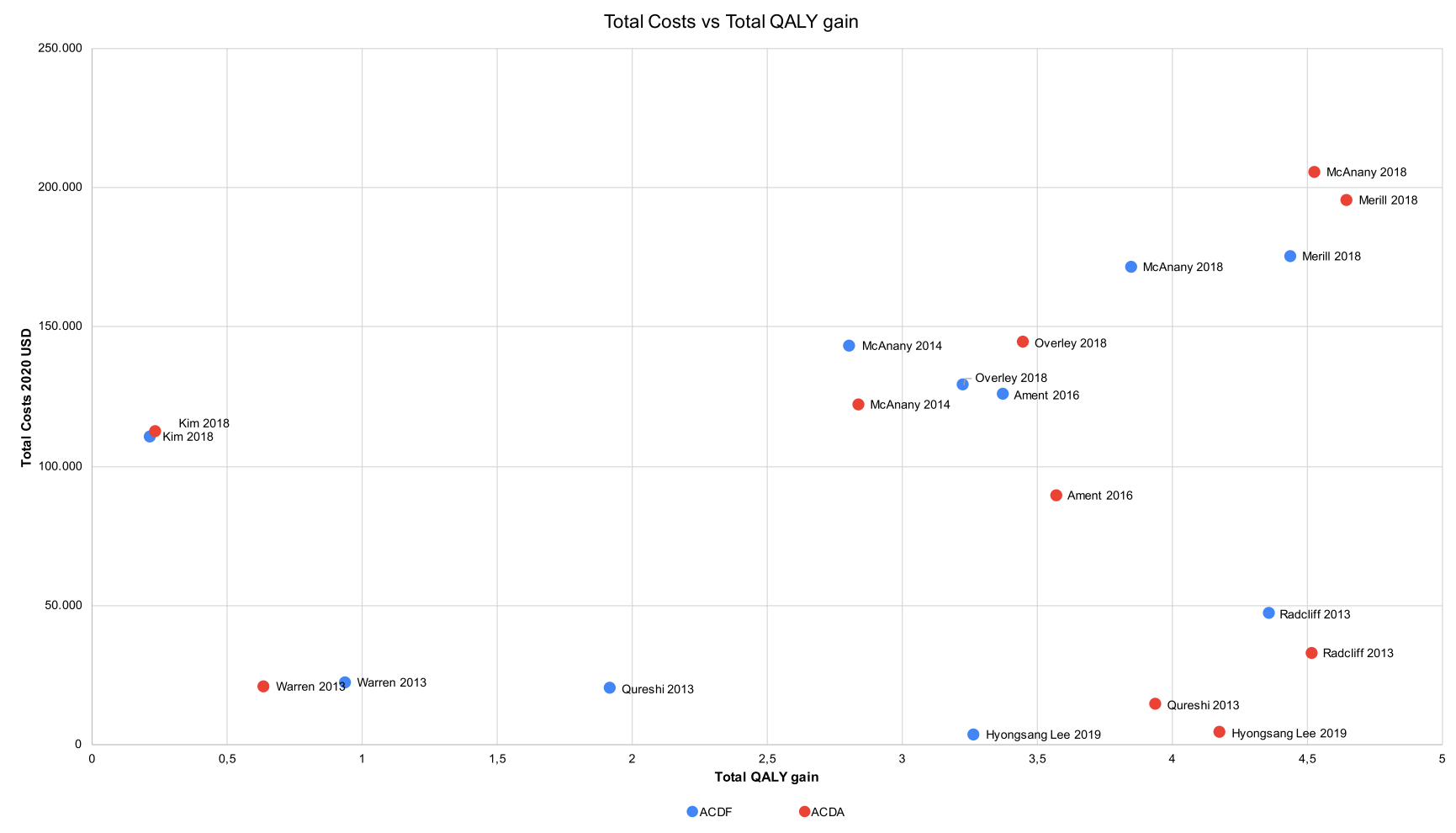

Fig. 2 A scatterplot displaying the total costs and total QALY gain for ACDA (red) and ACDF (blue) separately, as reported by the individual studies 


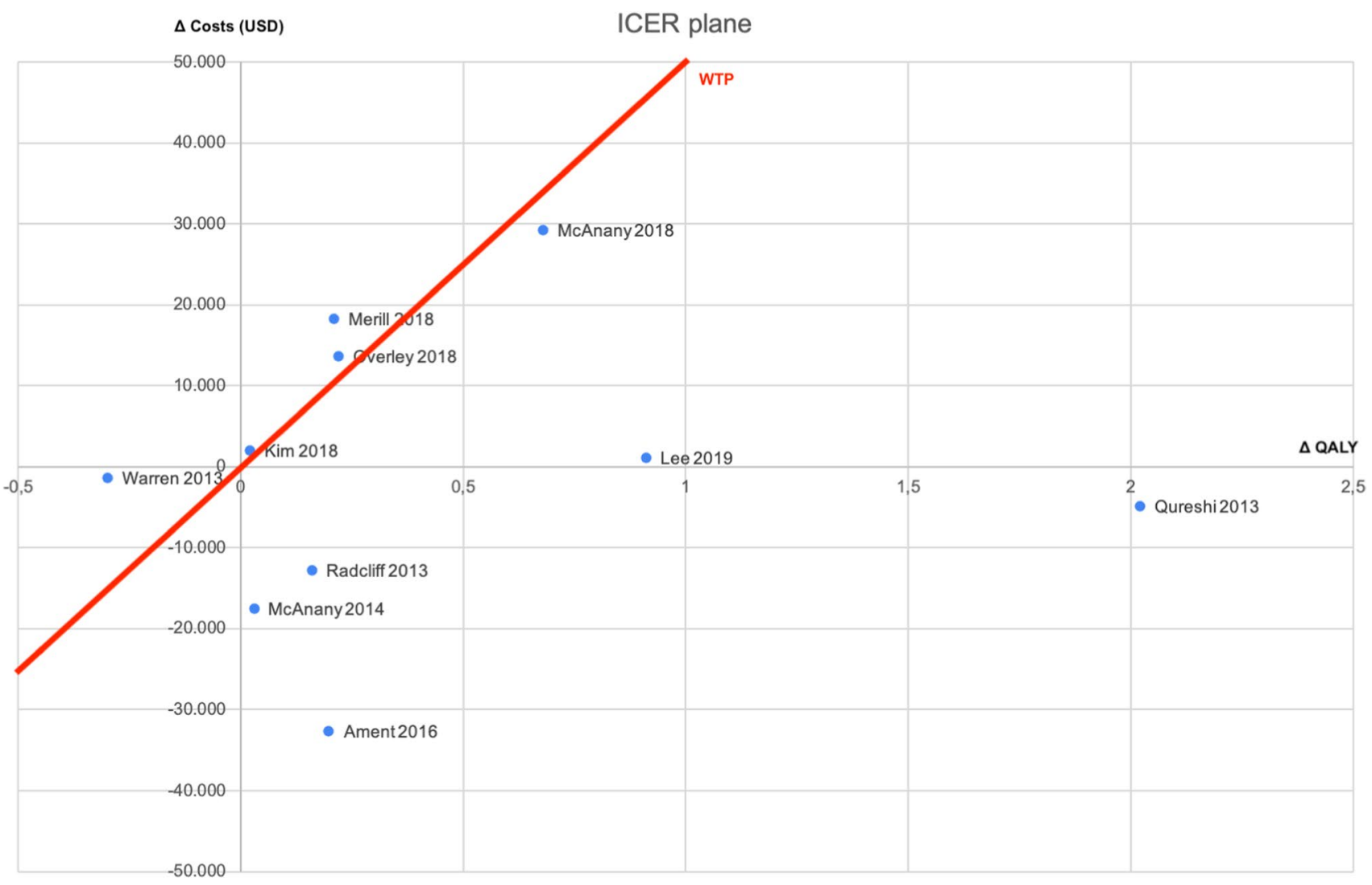

Fig. 3 The ICER plane of studies comparing ACDA to ACDF. The $Y$-axis represents the difference in costs (in 2020 USD), the $X$-axis represents the difference in QALY-gain. The red line represents the willingness-to-pay (WTP) threshold of \$50.000/QALY

\section{Conclusion}

This review evaluated cost-effectiveness of anterior surgical decompression techniques for radiculopathy and/or myelopathy due to CDDD. The most important result is the lack of uniform literature concerning the subject, which impedes any solid conclusions to be drawn. The results of this review show that both techniques are expensive. It seems that ACDA might be more cost-effective than ACDF as the majority of studies individually report ACDA to be the more cost-effective technique. In conclusion, there is a need for high-quality cost-effectiveness research and uniformity in reporting data to allow solid conclusions to be drawn.

Supplementary Information The online version contains supplementary material available at https://doi.org/10.1007/s00586-022-07137-7.

Funding None.

\section{Declarations}

Conflict of interest The authors declare that they have no conflict of interest.
Open Access This article is licensed under a Creative Commons Attribution 4.0 International License, which permits use, sharing, adaptation, distribution and reproduction in any medium or format, as long as you give appropriate credit to the original author(s) and the source, provide a link to the Creative Commons licence, and indicate if changes were made. The images or other third party material in this article are included in the article's Creative Commons licence, unless indicated otherwise in a credit line to the material. If material is not included in the article's Creative Commons licence and your intended use is not permitted by statutory regulation or exceeds the permitted use, you will need to obtain permission directly from the copyright holder. To view a copy of this licence, visit http://creativecommons.org/licenses/by/4.0/.

\section{References}

1. Abdulkarim JA, Dhingsa R, Finlay DBL (2003) Magnetic resonance imaging of the cervical spine: frequency of degenerative changes in the intervertebral disc with relation to age. Clin Radiol. https://doi.org/10.1016/S0009-9260(03)00255-1

2. European Commission-Eurostat (2019) Ageing Europe-looking at the lives of older people in the EU

3. Woods BI, Hilibrand AS (2015) Cervical radiculopathy: epidemiology, etiology, diagnosis, and treatment. J Spinal Disord Tech. https://doi.org/10.1097/BSD.0000000000000284 
4. Korinth MC (2008) Treatment of cervical degenerative disc disease-current status and trends. Zentralbl Neurochir 69(3):113124. https://doi.org/10.1055/s-2008-1081201

5. Neifert SN, Martini ML, Yuk F et al (2020) Predicting trends in cervical spinal surgery in the United States from 2020 to 2040. World Neurosurg 141:E175-E181. https://doi.org/10.1016/j.wneu. 2020.05.055

6. Hammer C, Heller J, Kepler C (2016) Epidemiology and pathophysiology of cervical disc herniation. Semin Spine Surg. https:// doi.org/10.1053/j.semss.2015.11.009

7. Roughley P, Martens D, Rantakokko J, Alini M, Mwale F, Antoniou J (2006) The involvement of aggrecan polymorphism in degeneration of human intervertebral disc and articular cartilage. Eur Cells Mater. https://doi.org/10.22203/eCM.v011a01

8. Fehlings MG, Ibrahim A, Tetreault L et al (2015) A global perspective on the outcomes of surgical decompression in patients with cervical spondylotic myelopathy. Spine (Phila Pa 1976). https://doi.org/10.1097/brs.0000000000000988

9. Donk RD, Verbeek ALM, Verhagen WIM, Groenewoud H, Hosman AJF, Bartels RHMA (2017) What's the best surgical treatment for patients with cervical radiculopathy due to single-level degenerative disease? a randomized controlled trial. PLoS ONE 12(8):e0183603. https://doi.org/10.1371/journal. pone. 0183603

10. Nandoe Tewarie RDS, Bartels RHMA, Peul WC (2007) Longterm outcome after anterior cervical discectomy without fusion. Eur spine J Off Publ Eur Spine Soc Eur Spinal Deform Soc Eur Sect Cerv Spine Res Soc. 16(9):1411-1416. https://doi.org/10. 1007/s00586-007-0309-y

11. Riew KD, Norvell DC, Chapman JR, Skelly AC, Dettori JR (2012) Introduction/summary statement: adjacent segment pathology. Spine (Phila Pa 1976). https://doi.org/10.1097/BRS.0b013e3182 6 cef01

12. Helgeson MD, Bevevino AJ, Hilibrand AS (2013) Update on the evidence for adjacent segment degeneration and disease. Spine $\mathbf{J}$ 13(3):342-351. https://doi.org/10.1016/j.spinee.2012.12.009

13. Seo M, Choi D (2008) Adjacent segment disease after fusion for cervical spondylosis; myth or reality? Br J Neurosurg 22(2):195199. https://doi.org/10.1080/02688690701790605

14. Eck JC, Humphreys SC, Lim T-H et al (2002) Biomechanical study on the effect of cervical spine fusion on adjacent-level intradiscal pressure and segmental motion. Spine (Phila Pa 1976) 27(22):2431-2434. https://doi.org/10.1097/00007632-20021 $1150-00003$

15. Hilibrand AS, Carlson GD, Palumbo MA, Jones PK, Bohlman HH (1999) Radiculopathy and myelopathy at segments adjacent to the site of a previous anterior cervical arthrodesis. J Bone Jt Surg-Ser A. https://doi.org/10.2106/00004623-199904000-00009

16. Lawrence BD, Hilibrand AS, Brodt ED, Dettori JR, Brodke DS (2012) Predicting the risk of adjacent segment pathology in the cervical spine: a systematic review. Spine (Phila Pa 1976). https:// doi.org/10.1097/BRS.0b013e31826d60fb

17. Vleggeert-Lankamp CLA, Janssen TMH, van Zwet E et al (2019) (2019) The NECK trial: effectiveness of anterior cervical discectomy with or without interbody fusion and arthroplasty in the treatment of cervical disc herniation; a double-blinded randomized controlled trial. Spine J 19(6):965-975. https://doi.org/ 10.1016/j.spinee.2018.12.013

18. Zhang Y, Liang C, Tao Y et al (2015) Cervical total disc replacement is superior to anterior cervical decompression and fusion: a meta-analysis of prospective randomized controlled trials. PLoS ONE. https://doi.org/10.1371/journal.pone.0117826

19. Nunley P, Michael H, Micah S, Marcus SM (2021) Cervical disc arthroplasty versus anterior cervical discectomy and fusion: 10 -year outcomes of a prospective randomized clinical trial at three sites. Unpublished data, Conference article CSRS, 2021.
20. Radcliff K, Davis RJ, Hisey MS et al (2017) Long-term evaluation of cervical disc arthroplasty with the mobi-C@ cervical disc: a randomized, prospective, multicenter clinical trial with seven-year follow-up. Int J Spine Surg 11(4):31. https://doi.org/10.14444/ 4031

21. Janssen ME, Zigler JE, Spivak JM, Delamarter RB, Darden BV 2nd, Kopjar B (2015) ProDisc-C total disc replacement versus anterior cervical discectomy and fusion for single-level symptomatic cervical disc disease: seven-year follow-up of the prospective randomized U.S. food and drug administration investigational device exemption stud. J Bone Joint Surg Am 97(21):1738-1747. https://doi.org/10.2106/JBJS.N.01186

22. Gornet MF, Burkus JK, Shaffrey ME, Schranck FW, Copay AG (2019) Cervical disc arthroplasty: 10-year outcomes of the prestige LP cervical disc at a single level. J Neurosurg Spine 31(3):317-325. https://doi.org/10.3171/2019.2.SPINE1956

23. Loidolt T, Kurra S, Riew KD, Levi AD, Florman J, Lavelle WF (2021) Comparison of adverse events between cervical disc arthroplasty and anterior cervical discectomy and fusion: a 10-year follow-up. Spine J Published online 2021. https://doi.org/ 10.1016/j.spinee.2020.10.013

24. Gornet MF, Lanman TH, Kenneth Burkus J et al (2019) One-level versus 2-level treatment with cervical disc arthroplasty or fusion: outcomes up to 7 years. Int J Spine Surg 13(6):551-560. https:// doi.org/10.14444/6076

25. Loumeau TP, Darden BV, Kesman TJ et al (2016) 2016) A RCT comparing 7-year clinical outcomes of one level symptomatic cervical disc disease (SCDD) following ProDisc-C total disc arthroplasty (TDA) versus anterior cervical discectomy and fusion (ACDF). Eur spine J Off Publ Eur Spine Soc Eur Spinal Deform Soc Eur Sect Cerv Spine Res Soc 25(7):2263-2270. https://doi. org/10.1007/s00586-016-4431-6

26. Davis RJ, Kim KD, Hisey MS et al (2013) Cervical total disc replacement with the Mobi-C cervical artificial disc compared with anterior discectomy and fusion for treatment of 2-level symptomatic degenerative disc disease: a prospective, randomized, controlled multicenter clinical trial: clinic. J Neurosurg Spine 19(5):532-545. https://doi.org/10.3171/2013.6.SPINE12527

27. Boselie TFM, Willems PC, van Mameren H, de Bie RA, Benzel EC, van Santbrink H (2013) Arthroplasty versus fusion in singlelevel cervical degenerative disc disease: a cochrane review. Spine (Phila Pa 1976) 38(17):E1096-107. https://doi.org/10.1097/BRS. 0b013e3182994a32

28. Findlay C, Ayis S, Demetriades AK (2018) Total disc replacement versus anterior cervical discectomy and fusion: a systematic review with meta-analysis of data from a total of 3160 patients across 14 randomized controlled trials with both short- and medium- to long- term outcomes. Bone Joint J 100B(8):9911001. https://doi.org/10.1302/0301-620X.100B8.BJJ-2018-0120. R1

29. Reyes AA, Canseco JA, Jeyamohan H, Grasso G, Vaccaro AR (2020) Financial aspects of cervical disc arthroplasty: a narrative review of recent literature. World Neurosurg 140:534-540. https:// doi.org/10.1016/j.wneu.2020.04.150

30. Alvin MD, Qureshi S, Klineberg E et al (2014) Cervical degenerative disease: systematic review of economic analyses. Spine (Phila Pa 1976). https://doi.org/10.1097/BRS.0000000000000547

31. Page MJ, Moher D (2017) Evaluations of the uptake and impact of the preferred reporting items for systematic reviews and metaanalyses (PRISMA) statement and extensions: a scoping review. Syst Rev. https://doi.org/10.1186/s13643-017-0663-8

32. Liberati A, Altman DG, Tetzlaff J et al (2009) The PRISMA statement for reporting systematic reviews and meta-analyses of studies that evaluate health care interventions: explanation and elaboration. J Clin Epidemiology 62(10):e1-e34. https://doi.org/ 10.1016/j.jclinepi.2009.06.006 
33. Thielen FW, Van Mastrigt GAPG, Burgers LT et al (2016) How to prepare a systematic review of economic evaluations for clinical practice guidelines: database selection and search strategy development (part 2/3). Expert Rev Pharmacoecon Outcomes Res. https://doi.org/10.1080/14737167.2016.1246962

34. Wijnen B, Van Mastrigt G, Redekop W, Majoie H, De Kinderen R, Evers SMAA (2016) How to prepare a systematic review of economic evaluations for informing evidence-based healthcare decisions: data extraction, risk of bias, and transferability (part 3/3). Expert Rev Pharmacoeconomics Outcomes Res. https://doi. org/10.1080/14737167.2016.1246961

35. van Mastrigt GAPG, Hiligsmann M, Arts JJC et al (2016) How to prepare a systematic review of economic evaluations for informing evidence-based healthcare decisions: a five-step approach (part 1/3). Expert Rev Pharmacoecon Outcomes Res. https://doi.org/ 10.1080/14737167.2016.1246960

36. Ouzzani M, Hammady H, Fedorowicz Z, Elmagarmid A (2016) Rayyan - a web and mobile app for systematic reviews. Syst Rev. https://doi.org/10.1186/s13643-016-0384-4

37. Bang H, Zhao H (2012) Median-based incremental cost-effectiveness ratio (ICER). J Stat Theory Pract. https://doi.org/10.1080/ 15598608.2012.695571

38. Evers S, Goossens M, De Vet H, Van Tulder M, Ament A (2005) Criteria list for assessment of methodological quality of economic evaluations: consensus on health economic criteria. Int J Technol Assess Health Care. https://doi.org/10.1017/s0266 462305050324

39. Cochrane handbook for systematic reviews of interventions (2019). https://doi.org/10.1002/9781119536604

40. Sterne JA, Hernán MA, Reeves BC et al (2016) ROBINS-I: a tool for assessing risk of bias in non-randomised studies of interventions. BMJ. https://doi.org/10.1136/bmj.i4919

41. Shemilt I, Thomas J, Morciano M (2010) A web-based tool for adjusting costs to a specific target currency and price year. Evid Policy. https://doi.org/10.1332/174426410X482999

42. The Nordic Cochrane Centre (2014) Review manager (RevMan). Cochrane Collab

43. Menzin J, Zhang B, Neumann PJ et al (2010) A health-economic assessment of cervical disc arthroplasty compared with allograft fusion. Tech Orthop. https://doi.org/10.1097/BTO.0b013e3181 de5769

44. Kim JS, Dowdell J, Cheung ZB et al (2018) The seven-year costeffectiveness of anterior cervical discectomy and fusion versus cervical disc arthroplasty: a Markov analysis. Spine (Phila Pa 1976) 43(22):1543-1551. https://doi.org/10.1097/BRS.00000 00000002665

45. Lee H, Kim UC, Oh JK et al (2019) Cost-effectiveness analysis of cervical anterior fusion and cervical artificial disc replacement in the Korean medical system. J Korean Neurosurg Soc 62(1):83-89. https://doi.org/10.3340/jkns.2018.0076LK-

46. Bhadra AK, Raman AS, Casey ATH, Crawford RJ (2009) Single-level cervical radiculopathy: clinical outcome and cost-effectiveness of four techniques of anterior cervical discectomy and fusion and disc arthroplasty. Eur Spine J. https://doi.org/10.1007/ s00586-008-0866-8

47. Ghori A, Konopka JF, Makanji H, Cha TD, Bono CM (2016) Long term societal costs of anterior discectomy and fusion (ACDF) versus cervical disc arthroplasty (CDA) for treatment of cervical radiculopathy. Int J Spine Surg 10:1. https://doi.org/10. $14444 / 3001$

48. Whitmore RG, Schwartz JS, Simmons S et al (2012) Performing a cost analysis in spine outcomes research: comparing ventral and dorsal approaches for cervical spondylotic myelopathy. Neurosurgery 70(4):860-867. https://doi.org/10.1227/NEU.0b013e3182 367272
49. Alvin MD, Lubelski D, Abdullah KG et al (2016) Cost-utility analysis of anterior cervical discectomy and fusion with plating (ACDFP) versus posterior cervical foraminotomy (PCF) for patients with single-level cervical radiculopathy. Clin spine Surg 29(2):E67-E72. https://doi.org/10.1016/j.spinee.2013.07.315

50. Witiw CD, Tetreault LA, Smieliauskas F, Kopjar B, Massicotte EM, Fehlings MG (2017) Surgery for degenerative cervical myelopathy: a patient-centered quality of life and health economic evaluation. Spine J. https://doi.org/10.1016/j.spinee.2016.10.015

51. Rihn JA, Bhat S, Grauer J et al (2019) Economic and outcomes analysis of recalcitrant cervical radiculopathy: is nonsurgical management or surgery more cost-effective? J Am Acad Orthop Surg 27(14):533-540. https://doi.org/10.5435/JAAOS-D-17-00379

52. Angevine PD, Zivin JG, McCormick PC et al (2005) (2005) Cost-effectiveness of single-level anterior cervical discectomy and fusion for cervical spondylosis. Spine (Phila $\mathrm{Pa} 1976$ ) 30(17):1989-1997. https://doi.org/10.1097/01.brs.0000176332. 67849.ea

53. Fernández-Fairen M, Murcia A, Torres A et al (2012) Is anterior cervical fusion with a porous tantalum implant a cost-effective method to treat cervical disc disease with radiculopathy? Spine (Phila Pa 1976) 37(20):1734-1741. https://doi.org/10.1097/BRS. 0b013e318255a184

54. Carreon LY, Anderson PA, Traynelis VC, Mummaneni PV, Glassman SD (2013) Cost-effectiveness of single-level anterior cervical discectomy and fusion five years after surgery. Spine (Phila Pa 1976) 38(6):471-475. https://doi.org/10.1097/BRS.0b013e3182 73aee2

55. Virk SS, Elder JB, Sandhu HS, Khan SN (2014) The cost effectiveness of polyetheretheketone (peek) cages for anterior cervical discectomy and fusion. J Spinal Disord Tech. https://doi.org/10. 1097/BSD.0b013e3182aa3676

56. Overley SC, McAnany SJ, Brochin RL, Kim JS, Merrill RK, Qureshi SA (2018) The 5-year cost-effectiveness of two-level anterior cervical discectomy and fusion or cervical disc replacement: a Markov analysis. Spine J 18(1):63-71. https://doi.org/10. 1016/j.spinee.2017.06.036

57. Chotai S, Parker SL, Sielatycki JA et al (2017) Impact of old age on patient-report outcomes and cost utility for anterior cervical discectomy and fusion surgery for degenerative spine disease. Eur spine J Off Publ Eur Spine Soc Eur Spinal Deform Soc Eur Sect Cerv Spine Res Soc 26(4):1236-1245. https://doi.org/10.1007/ s00586-016-4835-3

58. Whitmore RG, Schwartz JS, Simmons S, Stein SC, Ghogawala Z (2012) Performing a cost analysis in spine outcomes research: comparing ventral and dorsal approaches for cervical spondylotic myelopathy. Neurosurgery 70(4):860-867. https://doi.org/ 10.1227/NEU.0b013e3182367272

59. McAnany SJ, Merrill RK, Brochin RL et al (2018) Comparing the 5 -year health state utility value of cervical disc replacement and anterior cervical discectomy and fusion. Glob Spine J 8(1):6-10. https://doi.org/10.1177/2192568217721893

60. McAnany SJ, Overley S, Baird EO et al (2014) The 5-year costeffectiveness of anterior cervical discectomy and fusion and cervical disc replacement: a Markov analysis. Spine (Phila Pa 1976) 39(23):1924-1933. https://doi.org/10.1097/BRS.0000000000 000562

61. Merrill RK, McAnany SJ, Albert TJ et al (2018) Is two-level cervical disc replacement more cost-effective than anterior cervical discectomy and fusion at 7 years? Spine (Phila Pa 1976) 43(9):610-616. https://doi.org/10.1097/BRS.0000000000002380

62. Radcliff K, Lerner J, Yang C et al (2016) Seven-year cost-effectiveness of ProDisc-C total disc replacement: results from investigational device exemption and post-approval studies. J Neurosurg 
Spine 24(5):760-768. https://doi.org/10.3171/2015.10.SPINE 15505

63. Qureshi SA, McAnany S, Goz V, Koehler SM, Hecht AC (2013) Cost-effectiveness analysis: comparing single-level cervical disc replacement and single-level anterior cervical discectomy and fusion: clinical article. J Neurosurg Spine 19(5):546-554. https:// doi.org/10.3171/2013.8.SPINE12623

64. Ament JD, Yang Z, Nunley P, Stone MB, Lee D, Kim KD (2016) Cost utility analysis of the cervical artificial disc vs fusion for the treatment of 2-level symptomatic degenerative disc disease: 5-year follow-up. Neurosurgery 79(1):135-145. https://doi.org/10.1227/ NEU.0000000000001208

65. Warren D, Andres T, Hoelscher C, Ricart-Hoffiz P, Bendo J, Goldstein J (2013) Cost-utility analysis modeling at 2-year follow-up for cervical disc arthroplasty versus anterior cervical discectomy and fusion: a single-center contribution to the randomized controlled trial. Int J Spine Surg 7:e58-66. https://doi.org/10.1016/j. ijsp.2013.05.001

66. Witiw CD, Tetreault LA, Smieliauskas F, Kopjar B, Massicotte EM, Fehlings MG (2017) Surgery for degenerative cervical myelopathy: a patient-centered quality of life and health economic evaluation. Spine J 17(1):15-25. https://doi.org/10.1016/j.spinee. 2016.10.015

67. McAnany SJ, Merrill RK, Overley SC, Kim JS, Brochin RL, Qureshi SA (2018) Investigating the 7-year cost-effectiveness of single-level cervical disc replacement compared to anterior cervical discectomy and fusion. Glob Spine J 8(1):32-39. https://doi. org/10.1177/2192568217726283

68. Qureshi S, Goz V, McAnany S et al (2014) Health state utility of patients with single-level cervical degenerative disc disease: comparison of anterior cervical discectomy and fusion with cervical disc arthroplasty. Clinical article. J Neurosurg Spine 20(5):475479. https://doi.org/10.3171/2014.1.SPINE13718

69. Radcliff K, Zigler JJJ, Zigler JJJ et al (2015) Costs of cervical disc replacement versus anterior cervical discectomy and fusion for treatment of single-level cervical disc disease: an analysis of the blue health intelligence database for acute and long-term costs and complications. Spine (Phila Pa 1976) 40(8):521-529. https:// doi.org/10.1097/BRS.0000000000000822

70. Warren DT, Ricart-Hoffiz PA, Andres TM, Hoelscher CM, Protopsaltis TS, Goldstein JA, Bendo JA (2013) Retrospective cost analysis of cervical laminectomy and fusion versus cervical laminoplasty in the treatment of cervical spondylotic myelopathy. Int J Spine Surg 7(1):e72-e80. https://doi.org/10.1016/j.ijsp.2013.04. 001

71. Torres AF-FMAG, Murcia-Mazon A (2013) Anterior cervical fusion with tantalum implant: prospective randomized controlled study, five years follow up results. Eur Spine J 22(5):S694

72. Radcliff K, Guyer RD (2020) Economics of cervical disc replacement. Int J Spine Surg 14(2):S67-S72. https://doi.org/10.14444/ 7093

73. Weinstein MC, Siegel JE, Gold MR, Kamlet MS, Russell LB (1996) Recommendations of the panel on cost-effectiveness in health and medicine. J Am Med Assoc. https://doi.org/10.1001/ jama.276.15.1253

74. Hanmer J (2009) Predicting an SF-6D preference-based score using MCS and PCS scores from the SF-12 or SF-36. Value Heal. https://doi.org/10.1111/j.1524-4733.2009.00535.x

75. Hiligsmann M, Reginster J-Y, Tosteson ANA et al (2019) Recommendations for the conduct of economic evaluations in osteoporosis: outcomes of an experts' consensus meeting organized by the european society for clinical and economic aspects of osteoporosis, osteoarthritis and musculoskeletal diseases (ESCEO) an. Osteoporos Int J Establ Result Coop Between Eur Found Osteoporos Natl Osteoporos Found USA 30(1):45-57. https://doi.org/ 10.1007/s00198-018-4744-x

Publisher's Note Springer Nature remains neutral with regard to jurisdictional claims in published maps and institutional affiliations. 